\title{
Optimizing treatment of acute patients in a Danish Emergency Department Maria Søe Mattsson
}

Address: Akut afdeling Nykøbing F Sygehus, Nykøbing F, Denmark

Email: Maria Søe Mattsson - msmt@regionsjaelland.dk

from Danish Society for Emergency Medicine: Research Symposium 2009

Copenhagen, Denmark. 26 April 2009

Published: 20 August 2009

Scandinavian Journal of Trauma, Resuscitation and Emergency Medicine 2009, I7(Suppl 2):PI6 doi:10.1 I86/I757-724I-I7-S2-PI6

This abstract is available from: http://www.sjtrem.com/content/I7/S2/PI6

(C) 2009 Mattsson; licensee BioMed Central Ltd.

\section{Introduction}

The aim of this study was to observe and characterize the organization and quality of the treatment from a patient's point of view in a Danish Emergency Department.

\section{Methods}

The study is based on observations and data was conducted November 2008. Fifteen patients were included whereas five were stratified as medical patients, five were orthopedic and five were general surgical patients. There were nine male and six female patients with an age range of twenty-seven to ninety-one years. A neutral observer followed the patients with a semi structured observational method from arrival at the Emergency Department to the point of discharge aiming to clarify the process.

\section{Results}

The study identified that the different trade groups worked separately and the coordination of the patient treatment took place outside the trauma room thus resulting in an inadequate delivery of information between staff-members. In addition decisions made by one part of staff often got overruled by another, as the case is for visitation, and the trade groups has separate documentation forms. The doctor was often interrupted during one process having to relate to another before being able to proceed. Inexperienced doctors are in lack of guidance and the doctors in general have difficulties getting assistance from nurses. The patient is averagely seen fifteen minutes after arrival by one from the nursing staff and within an average of forty-two minutes by a doctor. The doctors specializing in internal medicine saw the patient faster than the surgeons. Fourteen out of fifteen patients where send home or to another medical profession within four hours. The patients expressed general satisfaction, no waiting time and where content with the information level.

\section{Conclusion}

If the key for development of an effective Emergency Department is taking care of the whole patient, it seems crucial to establish cross-functional teams with full utilization of the doctors' and nurses' respective competences as well as a tool compiling all the documentation gathered around one patient. If possible the decisions about treatment and further care should be made with the patient and nursing staff present to achieve the highest possible understanding of the patient's situation. 